\title{
STUDY ON THE NEED FOR JUDICIOUS PHYSICAL TRAINING OF JUNIOR DANCERS
}

\author{
Alin Cristian ROSA ${ }^{1 *}$ \\ 1 "1 Decembrie" University, Faculty of Physical Education and Sport, Alba Iulia, Romania \\ *Corresponding author: rosa.audio@yahoo.com
}

DOI: $10.35189 /$ iphm.icpesk.2019.41

\begin{abstract}
As in all performance sports, so also in dancesport, analysing the components of the training process, and especially their interdisciplinarity, is a sine qua non condition for achieving superior performance. In this context, given the higher and higher technical requirements, our paper aims to investigate the physical profile of junior 2 dancers, as a support for outstanding technical performance. Thus, our purpose is to assess their physical parameters and functional indices in order to determine the level of development of their motor skills, as a premise for a further extensive research that would demonstrate the degree of relationship of the physical training with the other components of the training process. The research methods used in our approach were: scientific documentation, pedagogical observation, experimental method, statistical and mathematical method, and graphical method. The research was conducted on a sample of 16 subjects ( 8 girls and 8 boys) aged between 14 and 15, " $D$ " class dancers, all involved in the competitive system of the Romanian DanceSport Federation. The statistical analysis of the obtained results has revealed that, although there were some differences between the two tests, they cannot be considered statistically significant, consequently the training methodology used (not the means and methods, but their dosing, their choice related to the stages of training) did not lead to higher indices of motor skills, the Student's t-test values validating the research hypothesis.
\end{abstract}

Keywords: dancesport, physical training, juniors.

\section{Introduction}

As in all performance sports, so also in dancesport, analysing the components of the training process, and especially their interdisciplinarity, is a sine qua non condition for achieving superior performance (Năstase, 2011).

In this context, given the higher and higher technical requirements, our paper aims to investigate the physical profile of junior 2 dancers, as a support for outstanding technical performance.

Starting from the premise that the sport performance is determined and conditioned multifactorially (besides the morphofunctional factors, the psychological ones being also involved) and represents the quintessence of the entire training activity of optimising the performance capacity (Manos, 2008), we are interested in the physical training as a component of the performance capacity of junior 2 dancers.

Purpose, objectives and tasks of the research

We aim to assess the physical parameters and functional indices of the research subjects in order to determine the level of development of their motor skills, as a premise for a further extensive research that would demonstrate the degree of relationship of the physical training with the other components of the training process.

Through our approach, we wanted to achieve the following objectives:

- $\quad$ establishing the level of development of the motor skills of the athletes included in the research using the Eurofit test battery and some specific tests;

- $\quad$ establishing the research programme for the basic scientific experiment.

In order to achieve these goals, we set the following research tasks:

- theoretical information on this issue in order to find out what has been addressed on this topic up to date;

- $\quad$ establishing the research sample;

- establishing the stages of our approach;

- choosing and applying the tests;

- data processing;

- drawing conclusions from the data analysis.

Hypothesis of the research

In our research, we intend to verify the following assumption: In the absence of clear objectives and effective methodology aimed at the physical training, the results in terms of development of the motor skills involved in the sport-specific effort cannot be consistent. 


\section{Material and Methods}

- Scientific documentation - involved studying Romanian and foreign bibliographical sources in order to obtain the most relevant and up-to-date information on the topic. These sources consisted of books, journals, the website of the Romanian DanceSport Federation, web pages, etc.

- Pedagogical observation - is based on the deliberate study of the phenomenon or the object under investigation to obtain pertinent information about it, which then allows rigorous scientific analysis.

- Experimental method - aims at verifying the hypothesis and is one of the representative research methods that helps draw the most relevant conclusions. Our experiment is an ascertaining one, because we wanted to establish the level of development of the motor skills in the research athletes.

- Statistical and mathematical processing - was done using the Excel and consisted in calculating several indicators such as arithmetic mean, standard deviation, mean deviation, and Student's t-test used to validate or invalidate the null hypothesis.

- Graphical method - graphical representation was used to express as efficiently as possible the processed data and the obtained results, but also as a way of analysing the research results.

- Measurement and assessments - the tests used in the research covered four categories of indices (Teodorescu, 2010):

a) somatic indicators ( 3 tests: body weight measurement, height measurement, body mass index BMI);

b) functional indicators ( 2 tests: heart rate measurement, Ruffier test) (Predescu \& Popescu, 2011);

c) indicators for general motricity ( 7 tests: Flamingo test, measurement of the mobility in the coxofemoral joint, tapping test, long-distance jump, crunches, holding hanged, 5 x $10 \mathrm{~m}$ shuttle) (EUROFIT 1988);

d) indicators for technical and physical execution (2 tests: Standard and Latin) (The Regulation of the Romanian DanceSport Federation 2017-2018).

- Technical evaluation method - in order to make a more objective assessment of the technical and physical tests, we used a judging-featured method by awarding grades in both initial testing (IT) and final testing (FT). The 5 panel evaluators are instructors at the ACS Top Dance 2007 Sports Club.

Examples of figures that composed the choreographies specific to the standard section were as follows:

Standard Section (Mihaiu \& Mihaiu, 2014):

- Slow Waltz: Natural spin turn, reverse pivot, progressive chasse, outside change ending in promenade position, running cross chasse, open right turn, back wisk, wing from PP, double reverse spin;

- Tango: walk x 2, promenade link, natural twist turn, close promenade, reverse turn, open promenade, outside swivel, rock, close promenade, back whisk, fall away promenade, four step, close promenade;

- Viennese Waltz: natural turn, forward change step natural to reverse, reverse turn, forward change step reverse to natural;

- Quickstep: natural spin turn, quarter turn to left, forward lock, natural turn, hesitation change, double reverse spin, telemark, fishtail, four quick run, running cross chasse, open right turn.

\section{The research sample}

The research was conducted on 16 subjects ( 8 girls and 8 boys) aged between 14 and 15, "D" class dancers, members of the ACS Top Dance 2007 Sports Club, all involved in the competitive system of the Romanian Dancesport Federation.

\section{Length and stages of the research}

The experimental research took place between July 2017 (initial testing) and June 2018 (final testing), respecting the training plan with 4 training sessions per week and weekend competitions (competitive period).

\section{Results}

\section{Somatic assessment results}

The arithmetic mean of the weight for the boys in our sample was $51.12 \mathrm{~kg}$ in initial testing and $52.12 \mathrm{~kg}$ in final testing. The $1-\mathrm{kg}$ difference is not statistically significant, because the calculated significance test, 1.52 , is less than the t-value at a significance threshold $>0.05$, thus assuming the null hypothesis. 
Another somatic indicator, the height, recorded $166.75 \mathrm{~cm}$ in initial testing and $168.62 \mathrm{~cm}$ in the final assessment. The increase of $1.87 \mathrm{~cm}$ from one assessment to another is statistically significant, because the Student's t-test has a value of 4.25 for $\mathrm{p}<0.05$, which rejects the null hypothesis. In other words, the training methods and means used did not negatively influence the growth processes characteristic of boys at this age.

In terms of BMI, there is no difference from one test to another in the case of boys and, even if their height has changed, weight fluctuations have made the average of this parameter to be 18.26 , which places them in the underweight category.

The mean values of the assessed somatic parameters are graphically represented in Figure 1.

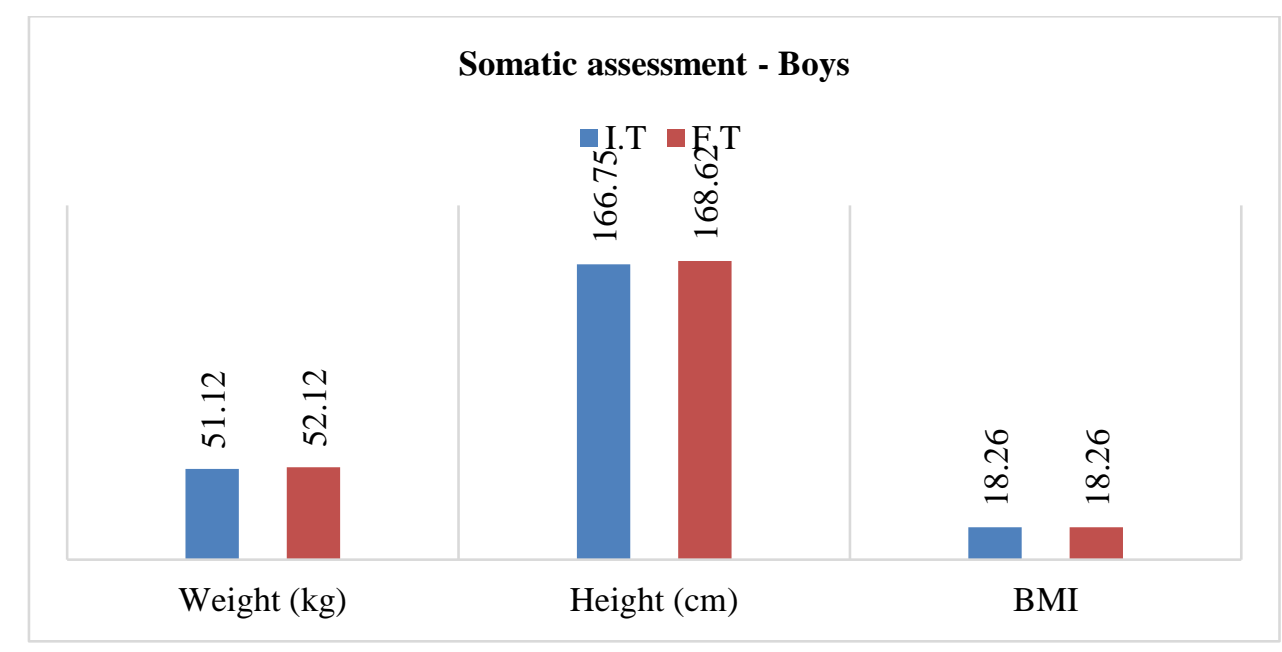

Figure 1. Graphical representation of mean values of the somatic indicators - Boys

In the case of girls, the weight recorded a difference of $0.63 \mathrm{~kg}$ that, for a t-value of 1.04 for $\mathrm{p}>0.05$, is not statistically significant, which confirms the null hypothesis.

The height increased from $157.5 \mathrm{~cm}$ in the initial test to 158.5 in the final test. By calculating the Student's ttest, a value of 3.05 is obtained for $p<0.05$, which leads to rejecting the null hypothesis and demonstrates the validity of the hypothesis that there are significant differences between the two tests. As with the tested boys, we can state that the training methodology used did not impede the growth processes characteristic of this age.

The average BMI in initial testing was 17.53 , while in the final test, the average value was 17.56 . By calculating the significance test, the value of 0.11 for $p>0.05$ was obtained. Thus, the null hypothesis is accepted, which means that the differences are not statistically significant. The average BMI values also place the girls in the underweight category. We can say that all subjects have a somatic aspect that meets the aesthetic requirements specific to dance.

The mean values of the assessed somatic parameters are graphically represented in Figure 2.

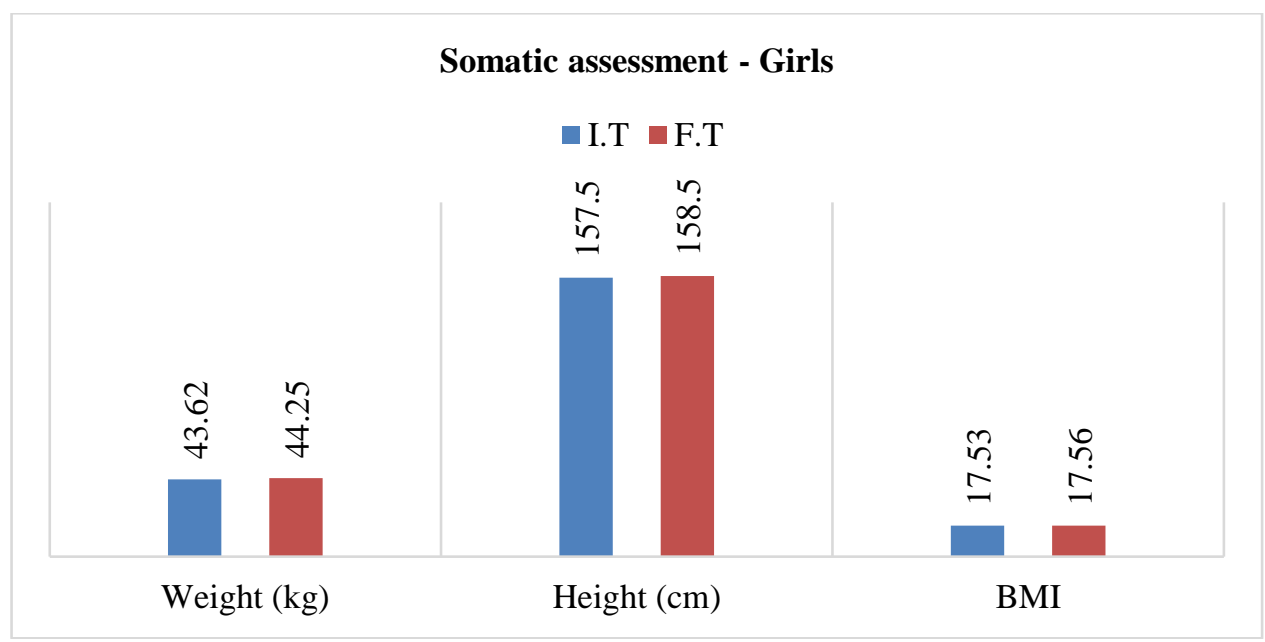

Figure 2. Graphical representation of mean values of the somatic indicators - Girls 


\section{Functional assessment results}

Table 1 shows the statistical indicators calculated for functional assessment in boys.

Table 1. Statistical indicators for functional assessment - Boys

\begin{tabular}{lcccccc}
\hline Functional indicators & \multicolumn{5}{c}{ Statistical indicators $(\mathrm{n}=8)$} & \\
\cline { 2 - 6 } & IT & FT & Statistical t & Tabular t & p & Significant/ \\
& $\overline{\boldsymbol{X}}$ & $\overline{\boldsymbol{X}}$ & & & & Insignificant for $\mathrm{p}=0.05$ \\
\hline Heart Rate $(\mathrm{bpm})$ & 201.75 & 201 & 2.39 & 2.36 & 0.04 & significant \\
Ruffier Index & 10.3 & 10 & 2.04 & 2.36 & 0.07 & insignificant \\
\hline
\end{tabular}

For boys, the average heart rate (HR) in initial testing was 201.75 beats per minute (bpm), while in the final assessment, it was $201 \mathrm{bpm}$. According to the Student's t-test value, 2.39, for $\mathrm{p}<0.05$, the difference between the two tests is statistically significant, thus rejecting the null hypothesis. Consequently, the training strategies used throughput our study positively influenced the functional demand for boys.

In another measured indicator, the Ruffier Index, the mean value is 10.3 in the initial test and 10 in the final test, these values showing that the boys have moderate adaptability to effort. The Student's t-test indicates a value of 2.04 for $\mathrm{p}>0.05$, which leads to the validation of the null hypothesis according to which the recorded differences are not statistically significant.

The mean values of the assessed functional parameters are graphically represented in Figure 3.

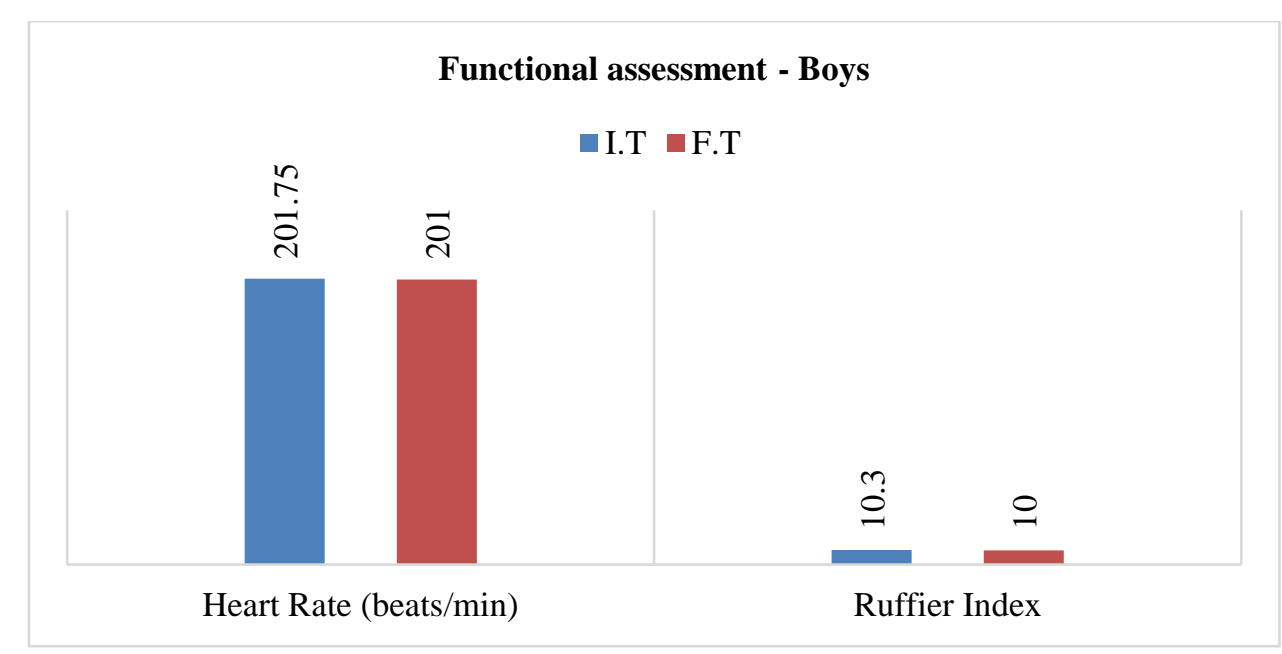

Figure 3. Graphical representation of mean values of the functional indicators - Boys

Table 2 shows the statistical indicators calculated for functional assessment in girls.

Table 2. Statistical indicators, functional assessment - Girls

\begin{tabular}{|c|c|c|c|c|c|c|}
\hline \multirow[t]{3}{*}{ Functional indicators } & \multicolumn{5}{|c|}{ Statistical indicators $(\mathrm{n}=8)$} & \multirow{3}{*}{$\begin{array}{c}\text { Significant/ } \\
\text { Insignificant for } \mathrm{p}=0.0\end{array}$} \\
\hline & IT & FT & Statistical t & Tabular t & $\mathrm{p}$ & \\
\hline & $\bar{X}$ & $\bar{X}$ & & & & \\
\hline Heart Rate (bpm) & 202.37 & 202.25 & 0.28 & 2.36 & 0.78 & Insignificant \\
\hline Ruffier Index & 10.62 & 10.12 & 1.87 & 2.36 & 0.10 & Insignificant \\
\hline
\end{tabular}

In girls, a HR value of 202.37 was recorded in the initial testing and a value of 202.25 in the final testing. For this functional indicator, the null hypothesis is confirmed because the Student's t-value is 0.28 for $\mathrm{p}>0.05$, so the differences between the two assessments are not statistically significant. 
Regarding the Ruffier Index, the average values of 10.62 in the initial test and 10.12 in the final test show that the girls have medium to low adaptability to effort. The significance test expressed a value of 1.87 for $p>0.05$ and therefore the differences are not statistically significant.

The mean values of the assessed functional parameters are graphically represented in Figure 4.

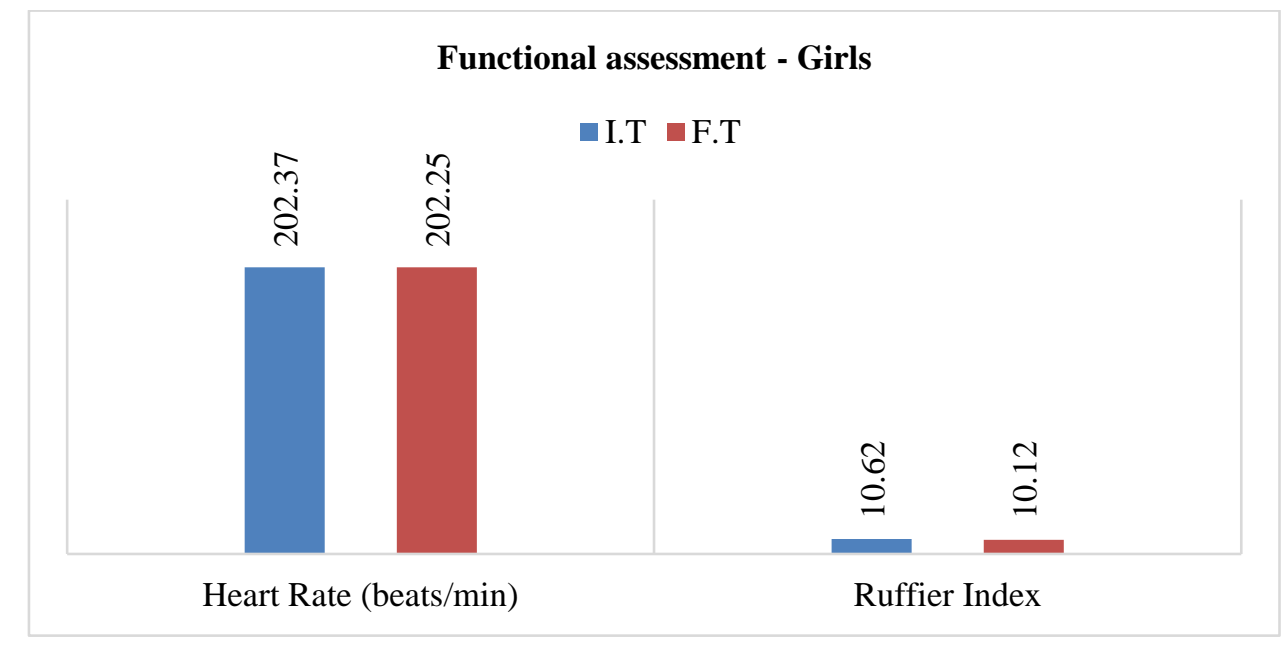

Figure 4. Graphical representation of mean values of the functional indicators - Girls

\section{Motor assessment results}

Table 3 shows the statistical indicators of motor assessment for boys, and Table 4, the statistical indicators of motor assessment for girls.

Table 3. Statistical indicators for motor assessment - Boys

\begin{tabular}{|c|c|c|c|c|c|c|}
\hline \multirow[t]{3}{*}{ Test } & \multicolumn{5}{|c|}{ Statistical indicators $(\mathrm{n}=8)$} & \multirow{3}{*}{$\begin{array}{c}\text { Significant/ } \\
\text { Insignificant for } p=0.05\end{array}$} \\
\hline & IT & FT & \multirow[t]{2}{*}{ Statistical t } & \multirow[t]{2}{*}{ Tabular $\mathrm{t}$} & \multirow[t]{2}{*}{$\mathrm{p}$} & \\
\hline & $\bar{X}$ & $\bar{X}$ & & & & \\
\hline Flamingo (pt.) & 4.37 & 3.87 & 1.87 & 2.36 & 0.10 & insignificant \\
\hline Mobility (cm) & 6.75 & 7.25 & 1.87 & 2.36 & 0.10 & insignificant \\
\hline Tapping test (sec) & 11.83 & 11.75 & 2.49 & 2.36 & 0.04 & significant \\
\hline Long jump (cm) & 167.62 & 168.12 & 1.87 & 2.36 & 0.10 & insignificant \\
\hline Crunches (reps/30 sec) & 24 & 24.62 & 1.92 & 2.36 & 0.09 & insignificant \\
\hline Holding hanged (sec) & 26.12 & 26.75 & 1.48 & 2.36 & 0.18 & insignificant \\
\hline Shuttle 10/5 m (sec) & 17.97 & 17.91 & 2.37 & 2.36 & 0.04 & significant \\
\hline \multirow{4}{*}{$\frac{\text { Table 4. Statistic }}{\text { Test }}$} & $f_{0 r}$ & ssessme & t-Girls & & & \\
\hline & \multicolumn{5}{|c|}{ Statistical indicators $(\mathrm{n}=8)$} & \\
\hline & IT & FT & Statistical t & Tabular $\mathrm{t}$ & $\mathrm{p}$ & Significant/ \\
\hline & $\bar{X}$ & $\bar{X}$ & & & & Insignificant for $\mathrm{p}=0.05$ \\
\hline Flamingo (pt.) & 4.87 & 4.5 & 1.15 & 2.36 & 0.28 & insignificant \\
\hline Mobility (cm) & 9.75 & 10.25 & 1.87 & 2.36 & 0.10 & insignificant \\
\hline Tapping test (sec) & 12.26 & 12.13 & 3.03 & 2.36 & 0.01 & significant \\
\hline Long jump (cm) & 165.37 & 166.12 & 2.39 & 2.36 & 0.04 & significant \\
\hline Crunches (reps/30 sec) & 24.25 & 24.62 & 1.15 & 2.36 & 0.28 & insignificant \\
\hline Holding hanged (sec) & 24.87 & 25.62 & 2.39 & 2.36 & 0.04 & significant \\
\hline Shuttle 10/5 m (sec) & 18.5 & 18.47 & 0.68 & 2.36 & 0.51 & insignificant \\
\hline
\end{tabular}

In the Flamingo Test from the Eurofit battery, boys achieved an average of 4.37 points in initial testing, while their average in the final test was 3.87. By calculating the significance test, the value of 1.87 for $\mathrm{p}>0.05$ was 
achieved. Thus, the null hypothesis is accepted, which means that the differences between the two assessments cannot be statistically significant.

In the case of girls, the average in the initial test was 4.87, and in the final assessment, 4.5. The difference between the two tests is not statistically significant, as the Student's t-test has the value 1.15 for $p>0.05$, so it can be said that the training methodology used had no consistent effects on the balance ability of the research subjects.

As regards mobility, for both boys and girls, there were differences between the averages obtained in the two tests, but in terms of the significance test ( 1.87 for both genders) for $\mathrm{p}>0.05$, but they cannot be considered statistically significant, so neither this motor component assessed has significantly improved during training.

In the Tapping Test, boys have progressed, because the difference between the mean values recorded in the two tests (IT $=11.83 \mathrm{sec}, \mathrm{FT}=11.75 \mathrm{sec}$ ), in the case of the significance test, of 2.49 for $\mathrm{p}<0.05$, is statistically significant.

The same thing happened in the case of the girls, the differences between the averages recorded in the two tests being statistically significant, because the calculation of the significance test revealed the value of 3.03 for $\mathrm{p}<$ 0.05 . In other words, the training strategy used during this period has positively influenced this psychomotor skill in both boys and girls.

Explosive leg power was assessed by the long jump test. There were no statistically significant differences in the case of boys, because, by calculating the significance test, the value of 1.87 for $p>0.05$ was obtained, which confirms the null hypothesis.

Unlike boys, the girls achieved an average of $165.37 \mathrm{~cm}$ in the initial test and, in the final test, an average of $166.12 \mathrm{~cm}$. There is an improvement in the results with $0.75 \mathrm{~cm}$, which, in the context of a significance test of 2.39 for $\mathrm{p}<0.05$, means a statistically significant difference.

For the test that measured the abdominal muscle strength for both boys and girls, the differences between the mean values recorded in the initial and final testing are not statistically significant, because the calculation of the significance test resulted in 1.92 (boys) and 1.15 (girls), which, for $\mathrm{p}>0.05$, confirms the null hypothesis. It can be said that the training methodology did not have the desired efficiency in terms of this motor component.

In the initial test of the holding hanged, the boys scored an average value of 26.12 seconds, and in the final test, the average value was 26.75 seconds. The progress of only $0.63 \mathrm{sec}$ is not statistically significant, because, by calculating the Student's t-test, 1.48 for $p>0.05$, the null hypothesis is accepted.

In the same test, the training methodology seemed to be effective for the girls, because the differences between the mean values of the two tests (IT $=24.87 \mathrm{sec}$ and FT $=25.62 \mathrm{sec}$ ) were statistically significant, in the context of a significance test of 2.39 for $\mathrm{p}<0.05$.

The shift speed with the change of direction was assessed by the Shuttle $(5 \times 10 \mathrm{~m})$ test. For boys, the differences between the mean values of the two tests are statistically significant, as the Student's t-test value of 2.37 was obtained for $\mathrm{p}<0.05$.

Not the same thing happened to the girls. They obtained an average value of 18.5 seconds in initial testing, improving their performance by only 0.03 seconds, a difference that is not statistically significant, because, by calculating the significance test, a value of 0.68 for $p>0.05$ was obtained.

The mean values of the assessed motor parameters are graphically represented in Figure 5 (boys) and Figure 6 (girls).

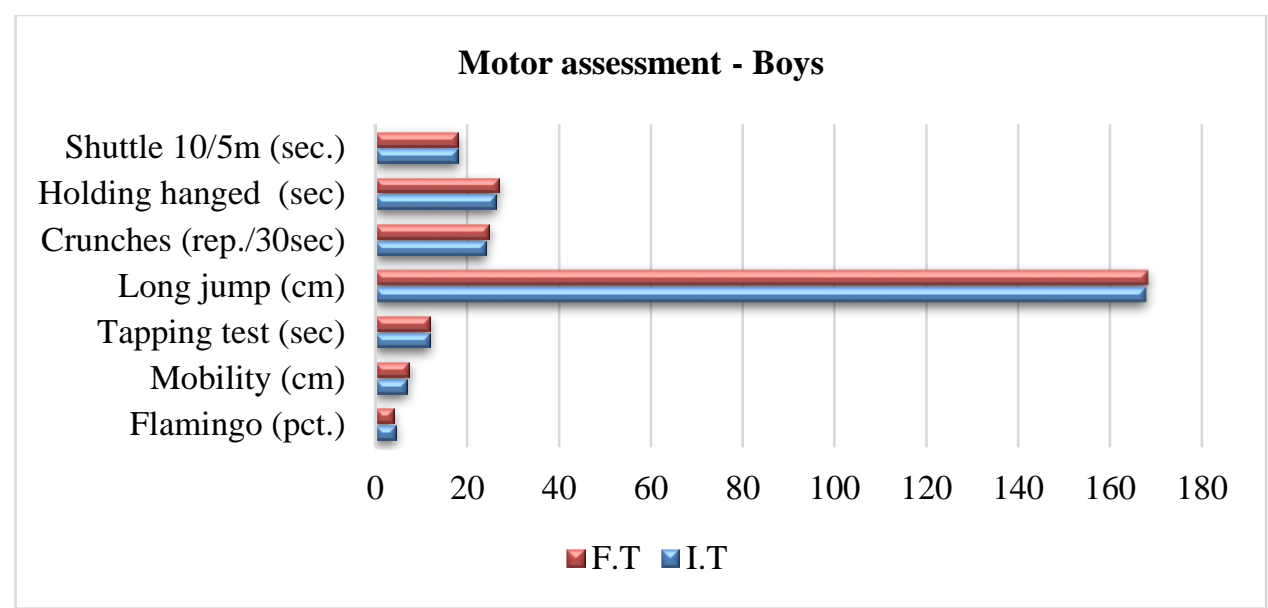

Figure 5. Graphical representation of mean values of the motor indicators - Boys 


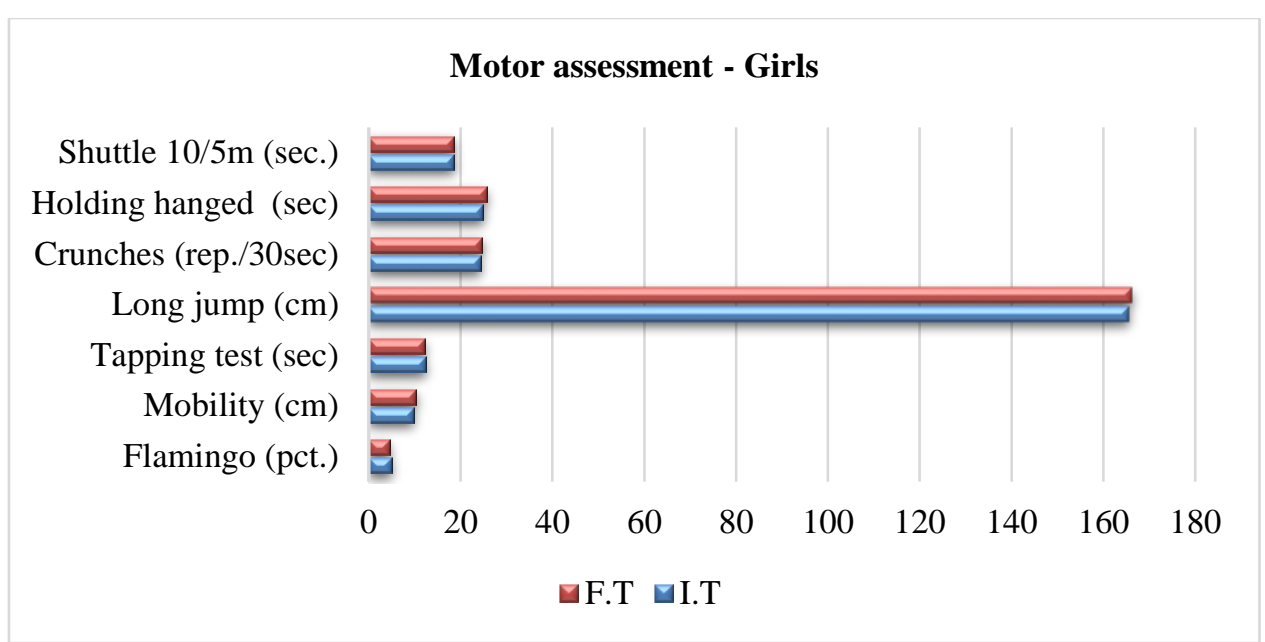

Figure 6. Graphical representation of mean values of the motor indicators - Girls

\section{Results of the technical-physical assessment}

The quality of Standard and Latin choreographies we designed in the technical and physical tests was judged by the grades awarded by a team of experts.

Even if they improved their scores from one test to another, neither the girls nor the boys, for both Standard and Latin choreographies, had statistically significant differences, because the calculated t-values were lower than the critical $\mathrm{t}$ for $\mathrm{p}>0.05$, which confirms the null hypothesis.

The average values of the grades obtained for Standard and Latin choreographies are graphically represented in Figure 7 (boys).

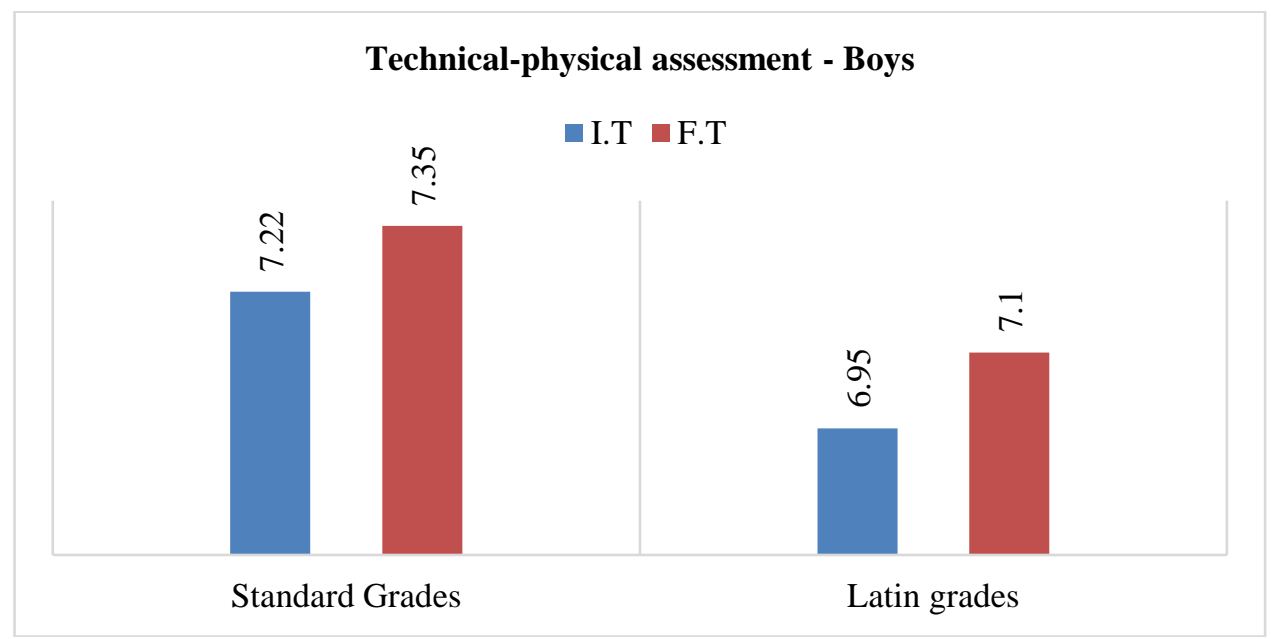

Figure 7. Graphical representation of average grades for Standard and Latin choreographies - Boys

\section{Conclusion}

- Regarding the somatic changes, we can say that they characterise the processes of growth and physical development of this age group.

- The statistical analysis of the results obtained in the assessment of functional indicators has revealed that, although there were some differences between the two tests, they cannot be considered statistically significant, consequently the effort adaptability of our subjects did not show a consistent improvement after preparation, the Student's t-test values validating the research hypothesis.

- Regarding the somatic sphere, in which we looked for the main motor skills that were assessed through the Eurofit test battery, we recorded statistically significant differences only in the intersegmental coordination test and the shift speed test (boys), while the girls progressed significantly on the Tapping Test, the long jump and the test that assessed the strength in the upper limbs. In other words, the training methodology used (not the means 
and methods, but their dosing, their choice related to the stages of training) did not lead to higher indices of motor skills, which confirms our hypothesis.

- We mention that the Dancesport Federation does not have centralised data on the motor profile of junior 2 dancers (as for any other category of dancers), which is why our approach has a conclusive value, being unable to compare the results obtained with a national average of this category.

- Regarding the quality of the technical executions assessed by our technical and physical tests, we did not record significant progress from one test to another, a sign that a low level of the main motor skills involved impeded the technical execution, this validating our research hypothesis

\section{References}

EUROFIT. (1988). Handbook for the Eurofit tests of physical fitness. Rome: Council of Europe, Committee for the Development of Sport.

Manos, M. (2008). Gimnastica ritmică: Capacitatea de performanţă [Rhythmic gymnastics: Performance capacity]. Bucureşti: Bren.

Mihaiu, F., \& Mihaiu, C. (2014). Introducere în dansurile standard [Introduction to Standard dances]. Bucureşti: Ars Docendi.

Năstase, V. D. (2011). Dans sportiv: Metodologia performanței [Dancesport: Performance methodology]. Pitești: Paralela 45.

Predescu, C., \& Popescu, A. D. (2011). Fiziologia efortului la copii și juniori [Exercise physiology in children and juniors]. Bucureşti: Discobolul.

Teodorescu, S. (2010). Teoria și metodica antrenamentului sportiv la copii și juniori [Sports theory and methodology for children and juniors]. Bucureşti: Discobolul. 